\title{
Basolateral Amygdala Lesions Facilitate Reward Choices after Negative Feedback in Rats
}

\author{
Alicia Izquierdo, ${ }^{1}$ Chelsi Darling, ${ }^{1}$ Nic Manos, ${ }^{1}$ Hilda Pozos, ${ }^{1}$ Charissa Kim,,${ }^{1}$ Serena Ostrander,,${ }^{1}$ Victor Cazares, ${ }^{1}$ \\ Haley Stepp, ${ }^{1}$ and Peter H. Rudebeck ${ }^{2}$ \\ ${ }^{1}$ Laboratory of Cognitive Neuroscience, Department of Psychology, California State University, Los Angeles, Los Angeles, California 90032, and ${ }^{2}$ Laboratory \\ of Neuropsychology, National Institute of Mental Health, National Institutes of Health, Bethesda, Maryland 20892
}

The orbitofrontal cortex (OFC) and basolateral amygdala (BLA) constitute part of a neural circuit important for adaptive, goal-directed learning. One task measuring flexibility of response to changes in reward is discrimination reversal learning. Damage to OFC produces well documented impairments on various forms of reversal learning in rodents, monkeys, and humans. Recent reports show that BLA, though highly interconnected with OFC, may be differentially involved in reversal learning. In the present experiment, we compared the effects of bilateral, ibotenic acid lesions of OFC or BLA (or SHAM) on visual discrimination and reversal learning. Specifically, we used pairwise visual discrimination methods, as is commonly administered in non-human primate studies, and analyzed how animals use positive and negative trial-by-trial feedback, domains not previously explored in a rat study. As expected, OFC lesions displayed significantly slower reversal learning than SHAM and BLA rats across sessions. Rats with BLA lesions, conversely, showed facilitated reversal learning relative to SHAM and OFC groups. Furthermore, a trial-by-trial analysis of the errors committed showed the BLA group benefited more from incorrectly performed trials (or negative feedback) on future choices than either SHAM or OFC rats. This provides evidence that BLA and OFC are involved in updating responses to changes in reward contingency and that the roles are distinct. Our results are discussed in relation to a competitive framework model for OFC and BLA in reward processing.

\section{Introduction}

In a variety of experimental species, lesions that include the orbitofrontal cortex (OFC) leave visual discrimination learning intact but impair performance when such learned reward contingencies are reversed, i.e., reversal learning (Jones and Mishkin, 1972; Dias et al., 1996; Chudasama and Robbins, 2003; McAlonan and Brown, 2003; Bissonette et al., 2008). The frontocortical localization of reversal learning appears to be well preserved across species (Chudasama, 2011; Izquierdo and Jentsch, 2012). In contrast to the well documented impairments after OFC lesions, less is known about the role of the basolateral amygdala (BLA) on reversal learning. Total amygdala lesions (not specific to BLA) fail to disrupt reversal learning in monkeys (Izquierdo and Murray, 2007) and BLA-specific lesions ameliorate OFC lesion-induced reversal learning impairments in rats (Stalnaker et al., 2007). Trial-by-trial analyses of object reversal learning in monkeys reveal that OFC-lesioned animals are less able to use feedback from correct trials for future trial choices, whereas monkeys with total amygdala lesions actually perform better than controls in their use of this information for subsequent choices (Rudebeck and Murray, 2008). Performance on a

\footnotetext{
Received Oct. 22, 2012; revised Jan. 9, 2013; accepted Jan. 16, 2013.

Author contributions: A.I. designed research; C.D., N.M., H.P., C.K., S.O., V.C., and H.S. performed research; A.I., C.D., C.K., S.O., and P.H.R. analyzed data; A.I. wrote the paper.

This work was supported by the NIH Minority Biomedical Research Support program at California State University, Los Angeles (CSULA). Partial support also came from NIMH (Grant SC2MH087974-03, to A.I.). We thank the CSULA Animal Care staff and the Russo-Neustadt and de Leon labs for technical support.

Correspondence should be addressed to Dr. Alicia Izquierdo, California State University, Los Angeles, 5151 State University Drive, Los Angeles, CA 90032. E-mail: aizquie@calstatela.edu.

DOI:10.1523/JNEUROSCI.4942-12.2013

Copyright $\odot 2013$ the authors $\quad 0270-6474 / 13 / 334105-05 \$ 15.00 / 0$
}

similar task of instrumental extinction is also facilitated by amygdala lesions in monkeys (Izquierdo and Murray, 2005), again in contrast to deficits following OFC lesions on this task. Together, this pattern of effects suggests a competitive relationship between OFC and BLA in adaptively responding to changes in reward contingency.

Methodological differences across reversal learning paradigms and species however, preclude agreement on the role for BLA in discrimination reversal learning. Previous investigations in rodents often use odor discrimination go/no-go paradigms (Schoenbaum et al., 2003; Stalnaker et al., 2007; Churchwell et al., 2009), not two-choice visual discrimination methods, the latter more commonly administered in monkey studies (Izquierdo and Murray, 2007). To explore this domain in the rat, we compared the effects of bilateral, ibotenic acid lesions of BLA or OFC on visual discrimination and reversal learning. Similar to previous reports using visual discriminative stimuli (Chudasama and Robbins, 2003; Izquierdo et al., 2010), we used customprogrammed touchscreen response methods developed to be analogous to methods used in monkeys (Dias et al., 1996; Rudebeck et al., 2008) and mice (Bussey et al., 2001; Izquierdo et al., 2006; Brigman et al., 2010; Barkus et al., 2012). An analysis of rats' trial-by-trial choices has also not been performed previously. To address this issue and to further probe the contribution of OFC and BLA to adaptive behavior, we also analyzed how rats use positive and negative feedback to guide future choices.

\section{Materials and Methods}

Subjects

Twenty-five male Long-Evans rats (Charles River Laboratories) weighing between 275 and $300 \mathrm{~g}$ at the beginning of the study were socially 
housed until food restriction commenced, were given water ad libitum, and were maintained at a $12 \mathrm{~h} \mathrm{light/dark} \mathrm{cycle,} \mathrm{with} \mathrm{the} \mathrm{temperature}$ constant at $22^{\circ} \mathrm{C}$. All behavioral testing took place 5-6 d per week between 8:00 A.M. and 6:00 P.M., consistent with previous studies in our laboratory (Izquierdo et al., 2010, 2012; Ostrander et al., 2011; Kosheleff et al., 2012). All procedures were approved by the Institutional Animal Care and Use Committee at California State University, Los Angeles.

\section{Apparatus}

Operant conditioning chambers $[35 \mathrm{~cm}$ (length) $\times 28 \mathrm{~cm}$ (width) $\times 34$ $\mathrm{cm}$ (height)] (\#80004, Lafayette Instrument Co.) were housed within sound- and light-attenuating cubicles (\#83018DDP, Lafayette Instrument Co.). Each chamber was equipped with an LCD touchscreen (Elo Touch). The houselight was located adjacent to the touchscreen, whereas the tone generator and pellet tray were located next to the pellet dispenser, opposing the touchscreen. The pellet dispenser delivered single $45 \mathrm{mg}$ dustless sucrose pellets (BioServ). Custom software (Ryklin Software Inc.) was used.

\section{Behavioral training}

General. Each session of training or testing lasted a maximum of $45 \mathrm{~min}$. Only a small area $(2.5 \mathrm{~cm}$ diameter circle) on the touchscreen was sensitive to nosepoking, while all other areas were programmed to be unresponsive. Criterion for advancement for each phase of pretraining was 60 correct nosepokes to the stimulus within $45 \mathrm{~min}$, on each of two consecutive days. During all postoperative phases, criterion for advancement was a minimum of $85 \%$ correct for two consecutive days, with a minimum of 60 correct nosepokes. The intertrial interval (ITI) increased from 0 to $5 \mathrm{~s}$ throughout pretraining and was maintained at $5 \mathrm{~s}$ for postoperative testing phases. Acclimation to single housing occurred 3 weeks upon arriving at the vivaria and $3 \mathrm{~d}$ before food restriction. Specific procedures for acclimation, handling, and food restriction have been reported in detail before (Izquierdo and Belcher, 2012; Kosheleff et al., 2012).

Food restriction and acclimation to food rewards. When rats had reached a minimum body weight of $275 \mathrm{~g}$, they were food-restricted to no less than $85 \%$ of their free-feeding body weight to ensure motivation to work for food, while water was available ad libitum. Weights were monitored three times per week to ensure a healthy body weight. Behavioral testing began no earlier than 1 week after the start of food restriction. On each of the $2 \mathrm{~d}$ before the start of testing, rats were fed 20 sucrose pellets in their home cage to accustom them to the food reward.

Autoshaping and pretraining. Autoshaping began with the display of white graphic stimuli on the black background of the touchscreen, the disappearance of which coincided with the onset of a "reward event": a sucrose pellet, a $1 \mathrm{~s}$ tone, and a $1 \mathrm{~s}$ illumination of the house light. An ITI of $20 \mathrm{~s}$ was used, while stimuli remained on the screen for $8 \mathrm{~s}$. At any time, rats could nosepoke the stimuli on the touchscreen and initiate the reward event. Criterion for autoshaping occurred when rats ate 60 sucrose pellets within $30 \mathrm{~min}$ for each of two consecutive days. After autoshaping, the pretraining phase commenced and consisted of four different stages previously outlined in detail (Kosheleff et al., 2012) in which rats progressively learned to nosepoke a "neutral" stimulus (i.e., a white circle). Criterion for advancement for each phase of training was 60 correct nosepokes within $45 \mathrm{~min}$, on each of two consecutive days. Upon finishing this stage of training, rats were taken off food restriction and allowed to free feed for either a minimum of $3 \mathrm{~d}$ or until all rats had completed pretraining.

\section{Surgery}

Rats received surgery after being handled and pretrained, but before discrimination and reversal learning. A subset of animals $(n=4$ from each of the three lesion groups) was assessed postoperatively on a brief test of effort ( $12 \mathrm{~d}$ ) before discrimination and reversal learning (see Data analysis). Methods for surgeries have been described in detail before (Ostrander et al., 2011). In brief, gas anesthesia was administered through a nosecone $(2-2.5 \%$, to effect) mounted on an ultra precise small animal stereotaxic headframe (Model 963, Kopf Instruments). Respiratory rate and body temperature were recorded every $2 \mathrm{~min}$. Small drill holes were made over the target sites and the Hamilton microliter syringe (Hamilton Co.) needle was lowered to infuse the neurotoxin, ibotenic acid, in $0.02 \mu \mathrm{l}$ increments. To mix the drug for surgery, $10 \mathrm{mg}$ of ibotenic acid (Sigma-Aldrich) was dissolved in $700 \mu$ l of $0.1 \mathrm{M} \mathrm{PBS}$, aliquoted to $7 \mu \mathrm{l}$ centrifuge tubes, and maintained at $-80^{\circ} \mathrm{C}$ until use.

Rats received bilateral injections of ibotenic acid in the BLA $(n=8)$ or OFC $(n=7)$ and sham-operated animals (SHAM, $n=10)$ received all operative procedures, but instead of neurotoxin, they received $0.1 \mathrm{M}$ PBS in the same sites ( $n=5$ OFC, $n=5 \mathrm{BLA}$ ). The OFC injections, directed at medial, ventral, and lateral sectors of the orbitofrontal cortex, were placed using coordinates from Chudasama and Robbins (2003), relative to bregma: Site $1(0.2 \mu \mathrm{l}), \mathrm{AP}=+4 \mathrm{~mm} ; \mathrm{ML}= \pm 0.8 ; \mathrm{DV}=-3.4 \mathrm{~mm}$; Site $2(0.2 \mu \mathrm{l}), \mathrm{AP}=+3.7 \mathrm{~mm} ; \mathrm{ML}= \pm 2.0 \mathrm{~mm} ; \mathrm{DV}=-3.6 \mathrm{~mm}$; Site 3 $(0.2 \mu \mathrm{l}), \mathrm{AP}=+3.2 \mathrm{~mm} ; \mathrm{ML}=2.6 \mathrm{~mm} ; \mathrm{DV}=-4.4 \mathrm{~mm}$. The injections directed at the BLA were as follows: Site $1(0.2 \mu \mathrm{l}) \mathrm{AP}=+2.8 \mathrm{~mm}$; ML, $\pm 5.0 \mathrm{~mm} ; \mathrm{DV}=-8.4 \mathrm{~mm}$; Site $2(0.1 \mu \mathrm{l}) \mathrm{AP}=+2.8 \mathrm{~mm} ; \mathrm{ML}, \pm 5.0$ $\mathrm{mm} ; \mathrm{DV}=-8.1 \mathrm{~mm}$ from bregma.

When injections were complete, the wound was closed using Vicryl absorbable sutures and swabbed with lidocaine $(2.5 \% \mathrm{w} / \mathrm{w})$ periodically for the first $24 \mathrm{~h}$. Rats were given a subcutaneous injection of $1.0 \mathrm{cc}$ of warmed $0.1 \mathrm{M}$ PBS and kept warm using a heating pad until ambulatory. They were then allowed $3-5 \mathrm{~d}$ to recover before postoperative testing.

\section{Postoperative testing}

Visual discrimination learning. When all rats had experienced 3-5 d of free-feeding and recovery following surgery, they were put back on food restriction and behavioral testing. In this phase, rats were presented with two novel, white, equiluminescent stimuli that differed only in shape (Izquierdo and Belcher, 2012; Izquierdo et al., 2012; $\mathrm{S}_{\mathrm{A}}$ and $\mathrm{S}_{\mathrm{B}}$ ) with predetermined reinforcement contingencies. The software enabled either a reward event as a result of nosepoking the correct stimulus ( + ), or a punishment as a result of nosepoking the incorrect stimulus ( $\mathrm{S}-$ ); the latter consisting of a $5 \mathrm{~s}$ "houselight off" and "time out" wherein rats were unable to initiate the next trial. If the rat committed an error and received a punishment, a correction trial was administered as previously described (Kosheleff et al., 2012). Stimuli presentation (i.e., left/right presentation of the $S+$ ) occurred pseudorandomly according to a Gellerman schedule. Stimulus assignment $\left(\mathrm{S}_{\mathrm{A}}{ }^{+} \mathrm{S}_{\mathrm{B}}{ }^{-}\right.$or $\left.\mathrm{S}_{\mathrm{A}}{ }^{-} \mathrm{S}_{\mathrm{B}}{ }^{+}\right)$was counterbalanced across treatment groups.

Reversal learning. Upon reaching criterion for the initial discrimination, rats were tested on a reversal of the reward contingencies: the stimulus that was initially rewarded resulted in punishment, and the stimulus that was previously punished was followed by a reward event. All other procedures for reversal learning testing were identical to the visual discrimination learning phase, above.

\section{Histology}

Standard procedures were used and have been extensively detailed by Ostrander et al. (2011). In brief, rats were killed an average of $177.7 \mathrm{~d}$ postsurgery with an overdose of Euthasol before being perfused transcardially with $250 \mathrm{ml}$ of $0.1 \mathrm{M}$ PBS followed by $250 \mathrm{ml}$ of $4 \%$ formaldehyde over $10 \mathrm{~min}$. Rat brains were extracted, soaked further in formaldehyde, and cryoprotected before staining with cresyl violet for Nissl bodies. Photomicrographs of representative lesions are shown in Figure 1. Reconstructions of the target areas have been published before (Ostrander et al., 2011).

\section{Data analyses}

Session data were analyzed using StatView software (SAS Institute), whereas trial-by-trial data were analyzed using SPSS. Statistical significance was noted when $p$-values were $\leq 0.05$, and a trend toward significance was noted when $p$-values were $0.06-0.08$. Data were collected for two postoperative phases: (1) initial visual discrimination learning and (2) reversal learning. Performance was analyzed on two measures: (1) sessions to criterion and (2) accuracy (percentage correct trials of total trials). The number of sessions required to reach criterion was analyzed using ANOVA. As learning rates differed across animals and to avoid overtraining the quickest learners (i.e., rats varied in the number of testing sessions to reach criterion), rats' two-session criterion run average of $85 \%$ or better was carried forward to complete later sessions (Izquierdo et al., 2010; Kosheleff et al., 2012). Overall analyses were conducted on the first $20 \mathrm{~d}$ of testing using repeated-measures ANOVA (rmANOVA), and, when interactions were significant, Fisher's protected least significant difference (PLSD) post hoc tests were conducted throughout. Trial-by-trial perfor- 

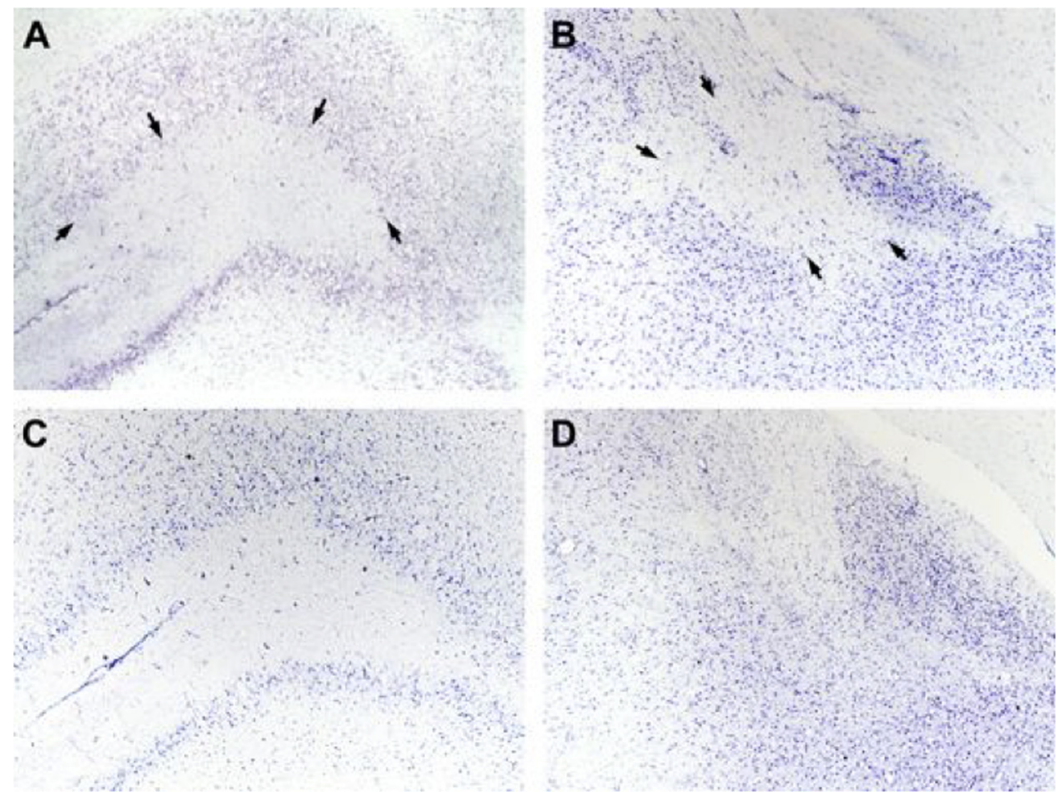

Figure 1. Representative photomicrographs of lesioned and intact OFC and BLA. $\boldsymbol{A}$, OFC lesion, left hemisphere, $+3.70 \mathrm{~mm}$ relative to bregma. Black arrows outlining the extent of the lesion most specific to ventral orbital cortex. $\boldsymbol{B}, \mathrm{BLA}$ lesion and central amygdala (CeA) nucleus, left hemisphere, $-2.80 \mathrm{~mm}$ relative to bregma. Black arrows outlining the extent of the lesion and sparing of cells in CeA. C, Intact OFC, left hemisphere, $+3.70 \mathrm{~mm}$ relative to bregma. $\boldsymbol{D}$, Intact BLA, left hemisphere, $-2.80 \mathrm{~mm}$ relative to bregma.

A

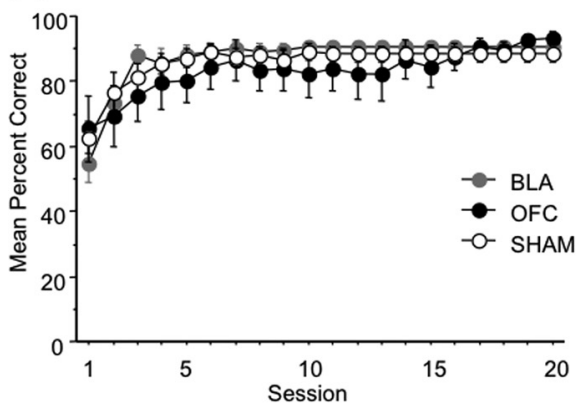

B

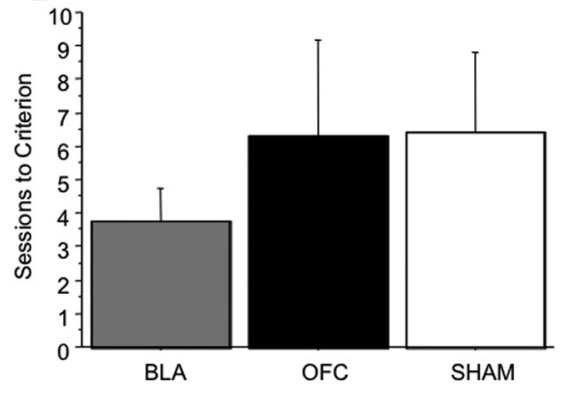

Figure 2. Discrimination learning is intact following OFC, BLA, or SHAM surgeries. $\boldsymbol{A}$, Mean percentage correct by session for the first 20 sessions of initial visual discrimination learning by lesion group. $\boldsymbol{B}$, Mean number of sessions to criterion by lesion group. Bars represent group means \pm SEM.

A

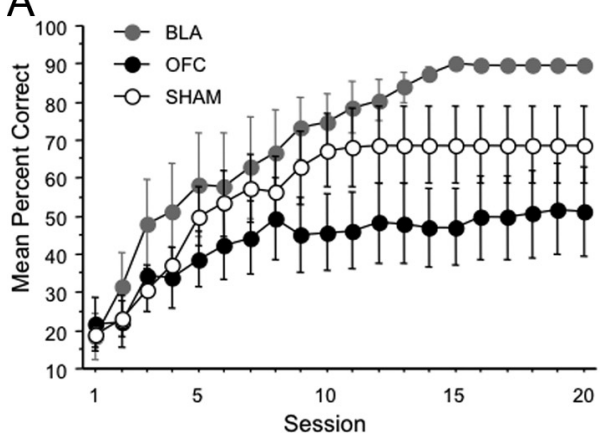

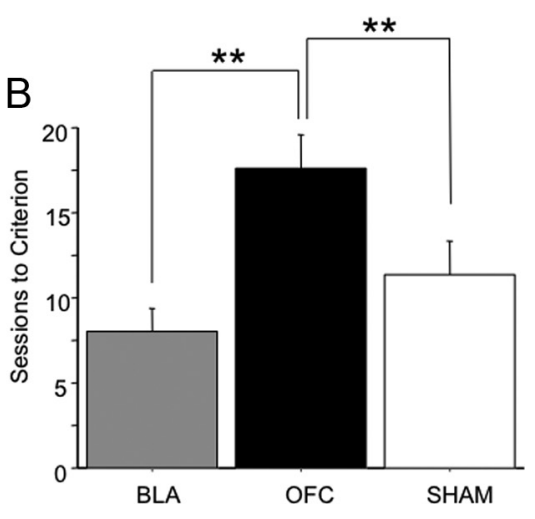

Figure 3. Reversal learning is facilitated by BLA lesion and impaired by OFC lesion relative to SHAM. $\boldsymbol{A}$, Mean percentage correct by session for first 20 sessions of reversal learning by lesion group. $\boldsymbol{B}$, Mean number of sessions to criterion by lesion group. Bars represent group means \pm SEM ${ }^{* *} p<0.01$. mance was also analyzed using rmANOVA with Fisher's PLSD for post hoc comparisons. The subset of rats $(n=12)$ with different training history was statistically identical to the cohort without additional training; thus, their group data are collapsed for all analyses below.

\section{Results}

Visual discrimination learning

Learning curves for the initial discrimination problem are shown in Figure 2A. An ANOVA revealed no significant group differences in sessions to criterion $\left(F_{(2,22)}=0.441, p=0.649\right.$; mean sessions to criterion: SHAM $=6.400 \pm$ 2.414 , OFC $=6.286 \pm 2.860$, BLA $=$ $3.750 \pm 0.977$; Fig. $2 B$ ). A rmANOVA on the first 20 sessions revealed no main effect of lesion group on accuracy (percentage correct: $\left.F_{(2,22)}=0.346, p=0.7115\right)$, and no significant interaction of session by lesion group on accuracy: $\left(F_{(38,418)}=\right.$ $1.243, p=0.1587)$. There was only a significant within-subject effect of session, showing all rats improved with experience $\left(F_{(19,418)}=22.730, p<0.0001\right)$.

\section{Reversal learning}

Upon reaching criterion on the original stimulus assignment, rats were tested on a reversal of the reward contingencies. An ANOVA showed that there was a significant lesion group difference in sessions to criterion $\left(F_{(2,22)}=6.331, p=0.0067\right.$; mean sessions to criterion: SHAM $=$ $11.400 \pm 1.945$, OFC $=17.571 \pm 1.974$, $\mathrm{BLA}=8.000 \pm 1.350$ ). Fisher's PLSD post hoc tests showed the OFC group required more sessions to learn than either BLA $(p=0.0019)$ or SHAM $(p=0.0261)$, but BLA was not significantly different from $\operatorname{SHAM}(p=0.1859)$. A rmANOVA on the first 20 sessions revealed a trend toward significance for lesion group on accuracy (percentage correct: $F_{(2,22)}=2.711, p=0.0886$ ), and a highly significant interaction of session by lesion group: $\left(F_{(38,418)}=1.992\right.$, $p=0.0006)$. Fisher's PLSD post hoc tests further revealed a significant difference between the BLA and OFC groups (percentage correct: BLA $>$ OFC, $p<0.0001$ ), OFC and SHAM groups (percentage correct: SHAM $>$ OFC, $p<0.0001)$, and BLA and SHAM groups (percentage correct: BLA $>$ SHAM, $p<0.0001$ ). Thus, when accuracy was analyzed across sessions (time), all three groups could be dissociated: the BLA group showing facilitated performance and the OFC group showing impaired performance relative to SHAM on reversal learning. Learning curves are shown in Figure $3 A$ and sessions to criterion in Figure $3 B$. 
A

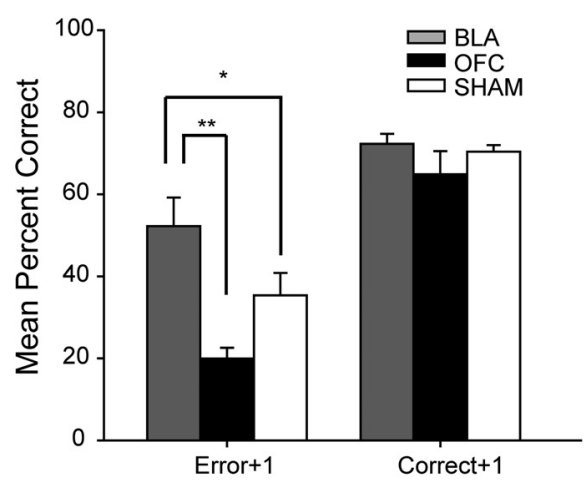

$\mathrm{B}$

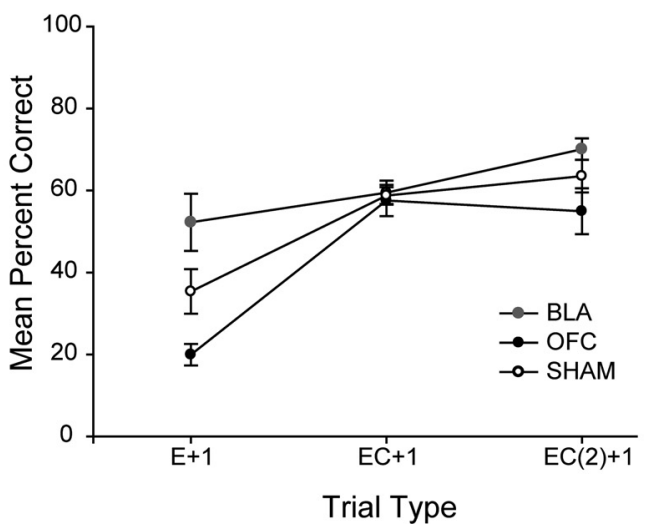

C

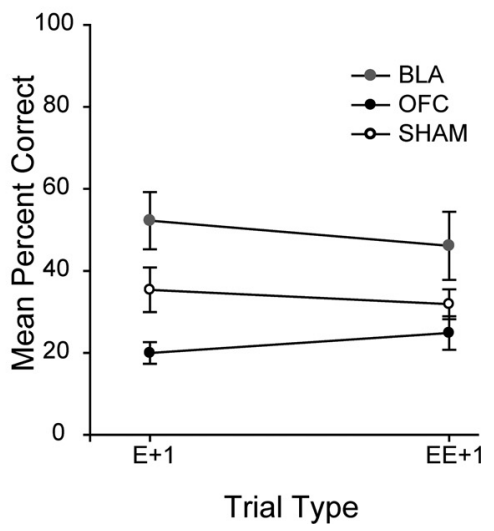

Figure 4. Trial-by-trial performance for BLA, OFC, and SHAM groups during reversal learning. A, Mean percentage correct following either negative (Error +1$)$ or positive $($ Correct +1$)$ feedback by lesion group. $\boldsymbol{B}$, Mean percentage correct following multiple trials where positive feedback (reward/correct trials) was delivered (EC analysis: $E+1-E C(2)+1)$ by lesion group. $C$, Mean percentage correct following multiple trials where negative feedback (unrewarded/error trials) was delivered (EE analysis: $E+1-E E+1$ ) by lesion group. Bars represent group means \pm SEM ${ }^{*} p \leq 0.05,{ }^{* *} p<0.01$.

\section{Trial-by-trial analyses}

Fine-grained, trial-by-trial analyses have been previously applied to monkey reversal learning data (Kennerley et al., 2006; Clarke et al., 2008; Rudebeck and Murray, 2008) and determine effect of positive feedback (rewarded choices, Correct +1 ) or negative feedback (unrewarded choices, Error +1 ) on subsequent choices. Analyses were conducted on all trials from the reversal learning phase of the experiment; however, due to loss of data, only a limited subset $(n=19)$ could be analyzed (BLA, $n=8$; SHAM $=$ 7 ; OFC = 4). A 2 (feedback) by 3 (lesion group) rmANOVA revealed that there was a significant effect of feedback type on accuracy (percentage correct: $F_{(1,16)}=62.53, p<0.001$ ) and lesion group on accuracy $\left(F_{(2,16)}=8.56, p=0.003\right)$ and a trend for a lesion group $\times$ feedback interaction $\left(F_{(2,16)}=2.99, p=\right.$ 0.079; Fig. 4A). Additional Fisher's PLSD post hoc tests revealed significant differences between BLA and SHAM groups (percentage correct: BLA $>$ SHAM, $p=0.037$ ), BLA and OFC groups (percentage correct: BLA $>$ OFC, $p=0.001$ ), and OFC and SHAM groups (percentage correct: SHAM $>$ OFC, $p=0.052$ ). Individual analyses of feedback type confirmed that BLA lesion rats were different from both SHAM and OFC groups on Error +1 (percentage correct: $F_{(2,16)}=6.35, p=0.009$; BLA $>$ SHAM, $p=0.048$, BLA $>$ OFC, $p=0.003$, SHAM $>$ OFC, $p=$ $0.126)$ but not Correct +1 trials $\left(F_{(2,16)}=1.5, p=0.253\right)$.

To further probe differences in the way rats were using both positive and negative feedback, additional analyses were conducted to assess the effect of strings of trials where rats received positive (EC analysis, Fig. $4 B$ ) or negative feedback (EE analysis, Fig. $4 C$ ). Only trial types where there were at least 10 instances for each animal were included. This meant that the EC analysis only included $\mathrm{E}+1-\mathrm{EC}(2)+1$ trial types $(\mathrm{E}=$ error, $\mathrm{C}=$ correct, therefore $\mathrm{EC}(2)+1$ is a sequence of $\mathrm{E}-\mathrm{C}-\mathrm{C}$ trials and then the +1 trial), and the $\mathrm{EE}$ analysis only included $\mathrm{E}+1$ and $\mathrm{EE}+1$ trial types. This analysis confirmed our previous finding that rats with BLA lesions were better able to use error feedback to guide subsequent choices: EE analysis, rmANOVA, effect of lesion group (percentage correct: $F_{(2,16)}=4.596, p=0.026$ ), Fisher's PLSD post hoc tests, BLA $>$ OFC, $p=0.011$, BLA $>$ SHAM, $p=0.064$, SHAM $>$ OFC, $p=0.254)$. Additionally, across strings of trials, they were able to use correct trial feedback more advantageously than the other groups: EC analysis, rmANOVA, effect of lesion group (percentage correct: $F_{(2,16)}=7.08, p=0.006$, Fisher's
PLSD post hoc tests BLA $>$ SHAM, $p=0.048$, BLA $>$ OFC, $p=$ 0.002 , SHAM $>$ OFC, $p=0.085$ ).

\section{Discussion}

In the present study, we report the novel finding of enhanced visual discrimination reversal learning in rats with BLA lesions. This facilitation stands in contrast to impaired reversal learning after OFC damage, a well substantiated impairment observed across rodent and non-human primates, and one we confirm here as well. The enhanced learning in BLA-lesioned rats was specific to the reversal learning phase, although we note this group also displayed rapid postoperative discrimination learning. Additionally, a fine-grained trial-by-trial analysis of reversal learning revealed that BLA rats were more likely to make a correct response after negative feedback (i.e., after committing either one error or experiencing strings of trials) than either SHAM or OFC rats.

OFC rats, conversely, were on average more likely to make an error after either type of feedback compared with either SHAM or BLA-lesioned rats, though this difference did not reach statistical significance. Our OFC lesion using stereotaxic coordinates from Chudasama and Robbins (2003) and Ostrander et al. (2011) is targeted more ventrally and less laterally than that which produces known (olfactory) reversal learning impairment (Schoenbaum et al., 2003). Thus, it is possible a more lateral OFC lesion would have produced an impairment on responses after negative feedback in visual discrimination reversal learning and a true double-dissociation of BLA and OFC effects. This is an empirical question for future investigation.

\section{Reversal learning enhancement after BLA lesions}

Previous studies of BLA-lesioned rats performing olfactory-based reversal tasks have yielded somewhat inconclusive results ranging from a mild impairment on a single reversal (Schoenbaum et al., 2003) to no appreciable reversal learning impairment (Stalnaker et al., 2007). Though the methodological differences between go/ no-go olfactory and visual discrimination reversal learning tasks are too numerous to review here and while each paradigm has its own merits, our novel result of enhanced reversal learning in rats with BLA lesions is likely enabled by the present study's use of a two-choice (pairwise comparison) paradigm. The presence of a second option interferes with the rat's ability to more efficiently 
reverse stimulus-reward associations. Thus, the present method may provide a differentially sensitive way to assess rat's reversal behavior and responses to positive and negative feedback. Additionally, in the present study, rats learned a single reversal to criterion, not several (serial) reversals, as in other reports. Daily sessions exposed rats to the same reward contingencies until criterion had been reached, a method similar to that previously administered in monkeys (Izquierdo and Murray, 2007). Last, as already mentioned, discrimination and reversal learning occurred in the visual modality in a non-spatial task, using two-dimensional stimuli and touchscreen response methods, instead of levers or magazine entries. Any or all of these differences might have contributed to our finding of enhanced reversal learning.

The pattern of reversal learning effects in Long-Evans rats is remarkably similar to those reported in non-human primate studies (Rudebeck and Murray, 2008). Though not a complete replication of effects, we confirm that BLA-lesioned animals display more adaptive choice behavior following feedback about reward. Here in the rat, we show enhanced performance in BLA rats after negative feedback, whereas Rudebeck and Murray (2008) found an enhancement after positive feedback in non-human primates. This could represent a species difference in reversal learning.

\section{OFC and BLA in a competitive framework}

The present results add to a growing list of opposing (not just dissociable) effects after OFC or BLA lesions on reward processing (Winstanley et al., 2004; Izquierdo and Murray, 2005; Rudebeck and Murray, 2008). BLA lesions may increase the sensitivity or salience of unrewarded trials (negative feedback) in rats and, instead, enhance the ability to represent contingency through other pathways. One candidate circuit involved in reward contingency is inferotemporal cortex (IT), rhinal cortex (Rh), and OFCimportant in the processing of sensory properties of reward and not its affective, hedonic value (Izquierdo and Murray, 2007; Rudebeck and Murray, 2008). Thus, eliminating the affective response to previously rewarded stimuli by removing the BLA may free a network comprising the IT-Rh-OFC to render an animal better able to switch response to sensory cues in reversal learning.

More recently, others have provided evidence that BLA and OFC exist in a competitive framework by showing "paradoxical facilitation" of attention in patients with Urbach-Wiethe disease (Morgan et al., 2012). In this view, the BLA functions to detect salience and bias attention in favor of the most relevant cue, a process of vital importance to survival. Therefore, if BLA is damaged, one would expect inhibited attentional bias, possibly leading to an enhanced ability to broaden attention and include other cues as relevant to the behavior. This could provide a mechanism for enhanced learning in BLA-lesioned animals, and represents an important avenue for future inquiry.

\section{References}

Barkus C, Feyder M, Graybeal C, Wright T, Wiedholz L, Izquierdo A, Kiselycznyk C, Schmitt W, Sanderson DJ, Rawlins JN, Saksida LM, Bussey TJ, Sprengel R, Bannerman D, Holmes A (2012) Do GluAl knock-out mice exhibit behavioral abnormalities relevant to the negative or cognitive symptoms of schizophrenia and schizoaffective disorder? Neuropharmacology 62:1263-1272. Medline

Bissonette GB, Martins GJ, Franz TM, Harper ES, Schoenbaum G, Powell EM (2008) Double dissociation of the effects of medial and orbital prefrontal cortical lesions on attentional and affective shifts in mice. J Neurosci 28:11124-11130. CrossRef Medline

Brigman JL, Mathur P, Harvey-White J, Izquierdo A, Saksida LM, Bussey TJ, Fox S, Deneris E, Murphy DL, Holmes A (2010) Pharmacological or genetic inactivation of the serotonin transporter improves reversal learning in mice. Cereb Cortex 20:1955-1963. CrossRef Medline
Bussey TJ, Saksida LM, Rothblat LA (2001) Discrimination of computergraphic stimuli by mice: a method for the behavioral characterization of transgenic and gene-knockout models. Behav Neurosci 115:957-960. CrossRef Medline

Chudasama Y (2011) Animal models of prefrontal-executive function. Behav Neurosci 125:327-343. CrossRef Medline

Chudasama Y, Robbins TW (2003) Dissociable contributions of the orbitofrontal and infralimbic cortex to pavlovian autoshaping and discrimination reversal learning: further evidence for the functional heterogeneity of the rodent frontal cortex. J Neurosci 23:8771-8780. Medline

Churchwell JC, Morris AM, Heurtelou NM, Kesner RP (2009) Interactions between the prefrontal cortex and amygdala during delay discounting and reversal. Behav Neurosci 123:1185-1196. CrossRef Medline

Clarke HF, Robbins TW, Roberts AC (2008) Lesions of the medial striatum in monkeys produce perseverative impairments during reversal learning similar to those produced by lesions of the orbitofrontal cortex. J Neurosci 28:10972-10982. CrossRef Medline

Dias R, Robbins TW, Roberts AC (1996) Primate analogue of the Wisconsin Card Sorting Test: effects of excitotoxic lesions of the prefrontal cortex in the marmoset. Behav Neurosci 110:872-886. CrossRef Medline

Izquierdo A, Belcher AM (2012) Rodent models of adaptive decision making. Methods Mol Biol 829:85-101. CrossRef Medline

Izquierdo A, Jentsch JD (2012) Reversal learning as a measure of impulsive and compulsive behavior in addictions. Psychopharmacology (Berl) 219: 607-620. CrossRef

Izquierdo A, Murray EA (2005) Opposing effects of amygdala and orbital prefrontal cortex lesions on the extinction of instrumental responding in macaque monkeys. Eur J Neurosci 22:2341-2346. CrossRef Medline

Izquierdo A, Murray EA (2007) Selective bilateral amygdala lesions in rhesus monkeys fail to disrupt object reversal learning. J Neurosci 27:1054-1062. CrossRef Medline

Izquierdo A, Wiedholz LM, Millstein RA, Yang RJ, Bussey TJ, Saksida LM, Holmes A (2006) Genetic and dopaminergic modulation of reversal learning in a touchscreen-based operant procedure for mice. Behav Brain Res 171:181-188. CrossRef Medline

Izquierdo A, Belcher AM, Scott L, Cazares VA, Chen J, O’Dell SJ, Malvaez M, Wu T, Marshall JF (2010) Reversal-specific learning impairments after a binge regimen of methamphetamine in rats: possible involvement of striatal dopamine. Neuropsychopharmacology 35:505-514. CrossRef Medline

Izquierdo A, Carlos K, Ostrander S, Rodriguez D, McCall-Craddolph A, Yagnik G, Zhou F (2012) Impaired reward learning and intact motivation after serotonin depletion in rats. Behav Brain Res 233:494-499. CrossRef Medline

Jones B, Mishkin M (1972) Limbic lesions and the problem of stimulusreinforcement associations. Exp Neurol 36:362-377. CrossRef Medline

Kennerley SW, Walton ME, Behrens TE, Buckley MJ, Rushworth MF (2006) Optimal decision making and the anterior cingulate cortex. Nat Neurosci 9:940-947. CrossRef Medline

Kosheleff AR, Rodriguez D, O’Dell SJ, Marshall JF, Izquierdo A (2012) Comparison of single-dose and extended methamphetamine administration on reversal learning in rats. Psychopharmacology (Berl) 224:459-467. CrossRef

McAlonan K, Brown VJ (2003) Orbital prefrontal cortex mediates reversal learning and not attentional set shifting in the rat. Behav Brain Res 146: 97-103. CrossRef Medline

Morgan B, Terburg D, Thornton HB, Stein DJ, van Honk J (2012) Paradoxical facilitation of working memory after basolateral amygdala damage. PLoS One 7:e38116. CrossRef Medline

Ostrander S, Cazares VA, Kim C, Cheung S, Gonzalez I, Izquierdo A (2011) Orbitofrontal cortex and basolateral amygdala lesions result in suboptimal and dissociable reward choices on cue-guided effort in rats. Behav Neurosci 125:350-359. CrossRef Medline

Rudebeck PH, Murray EA (2008) Amygdala and orbitofrontal cortex lesions differentially influence choices during object reversal learning. J Neurosci 28:8338-8343. CrossRef Medline

Rudebeck PH, Behrens TE, Kennerley SW, Baxter MG, Buckley MJ, Walton ME, Rushworth MF (2008) Frontal cortex subregions play distinct roles in choices between actions and stimuli. J Neurosci 28:13775-13785. CrossRef Medline

Schoenbaum G, Setlow B, Nugent SL, Saddoris MP, Gallagher M (2003) Lesions of orbitofrontal cortex and basolateral amygdala complex disrupt acquisition of 
odor-guided discriminations and reversals. Learn Mem 10:129-140. CrossRef Medline

Stalnaker TA, Franz TM, Singh T, Schoenbaum G (2007) Basolateral amygdala lesions abolish orbitofrontal-dependent reversal impairments. Neuron 54:51-58. CrossRef Medline
Winstanley CA, Theobald DE, Cardinal RN, Robbins TW (2004) Contrasting roles of basolateral amygdala and orbitofrontal cortex in impulsive choice. J Neurosci 24:4718-4722. CrossRef Medline 